\title{
Tongue metastasis as an initial manifestation of metastasis in renal cell carcinoma: A case report
}

\author{
Mutahar A. Tunio ${ }^{1}$, Mushabbab Al-Asiri ${ }^{2}$, Shoaib Ahmad ${ }^{1}$, Mohsin Fareed ${ }^{1}$ \\ 1. Assistant Consultants Radiation Oncology. 2. Department of Radiation Oncology, Comprehensive Cancer Center, King \\ Fahad Medical City, Riyadh, Saudi Arabia
}

Correspondence: Mutahar A. Tunio. Address: Radiation Oncology, King Fahad Medical City, P.O. Box 59046 Riyadh, 11525, Kingdom of Saudi Arabia. Telephone: 966-1288-9999. Fax: 966-1461-4006.

E-mail: drmutahirtonio@hotmail.com

Received: September 15, 2011 Accepted: December 28, 2011 Published: April 1, 2012

DOI : $10.5430 /$ jst.v2n2p39

URL: http://dx.doi.org/10.5430/jst.v2n2p39

\begin{abstract}
Renal cell carcinoma (RCC) has unpredictable and diverse behavior. The classic triad of hematuria, loin pain and abdominal mass is uncommon. About $25 \%-30 \%$ of patients are found to have metastases at the time of diagnosis. Bones, lungs, liver and brain are the frequent sites of metastases. RCC with metastasis to the oral cavity is rarest manifestation. We report a case of 35 years old male who underwent radical nephrectomy for localized RCC six years back, now presented with mass in the base of tongue which was suspected as carcinoma of tongue; subsequently was confirmed as metastatic RCC following excisional biopsy and was treated with intra-oral electron radiation therapy.
\end{abstract}

\section{Key words}

Renal cell carcinoma, Metastasis, Carcinoma

\section{Introduction}

Renal cell carcinoma (RCC) has unpredictable and diverse behavior. The incidence of RCC over last 20 years has progressively increased due to widespread use of modern imaging ${ }^{[1]}$. About $30 \%-50 \%$ of patients are found to have metastases at diagnosis. While bone, lymph nodes, lungs and brain constitute expected 'homing' sites, metastasis may turn up at the unusual locations (skin, testis and maxillary antrum) ${ }^{[2,3]}$.

Metastasis to the head and neck region from primary abdominal malignancies is rarest. Lung and breast carcinomas are the commonest malignancies to metastasize to the head and neck region ${ }^{[4]}$. The common presenting symptoms of metastatic RCC in the head and neck region are; enlarged solitary mass, epistaxis, nasal obstruction and lymphadenopathy, depending on the location and the extent of invasion by metastatic deposits ${ }^{[5]}$.

Herein, a rare case of base of tongue metastasis, following an open radical nephrectomy six years back in a 35 years old male with a stage pT2NOM0 and Fuhrman grade II renal cell carcinoma, is reported. 


\section{Case report}

A 35 years old man presented with painless swelling in right lateral tongue for two months. Past history revealed the previous history of right radical nephrectomy. The final pathologic finding of renal mass was consistent with papillary cell type renal cell carcinoma, which was not infiltrating through the capsule, hilar vessels and margins were free of tumor. Stage was made pT2N0M0.

On physical examination, there was hard fixed palpable superficial mass at right lateral border of tongue of size $3 \mathrm{~cm} \times 3$ $\mathrm{cm}$. borders were ill defined, no ulceration and non-tender to touch (Figure 1). The rest of examination was normal. CT head and neck showed $3 \mathrm{~cm} \times 3.5 \mathrm{~cm}$ soft tissue mass involving right lateral tongue and adjacent glossal muscles. CT chest and abdomen were positive for lung metastases, but bone scan was negative for osseous metastases. Differential diagnosis was primary carcinoma of tongue or metastatic lesion of renal cell carcinoma. Excisional biopsy of tongue showed neoplastic cells with nuclear atypia, vascular invasion positive, and immunohistochemistry showed vimentin, CD-10, pan-CK, EMA and S-100 positivity, which confirmed the diagnosis of metastatic renal cell carcinoma (Figure 2). After excision, patient received palliative radiotherapy (total dose $30 \mathrm{~Gy}$ in 10 fractions) to gross tumor volume with intra-oral electron therapy using $5 \mathrm{~cm}$ acrylic applicator (Figure 3). Following completion of radiotherapy, he was started on oral sunitinib $50 \mathrm{mg}$ daily. On his last follow up, there was no visualization of tumor in tongue.

Figure 1. Physical examination showing a hard fixed palpable superficial mass at base of tongue with extension into lateral margin of oral tongue

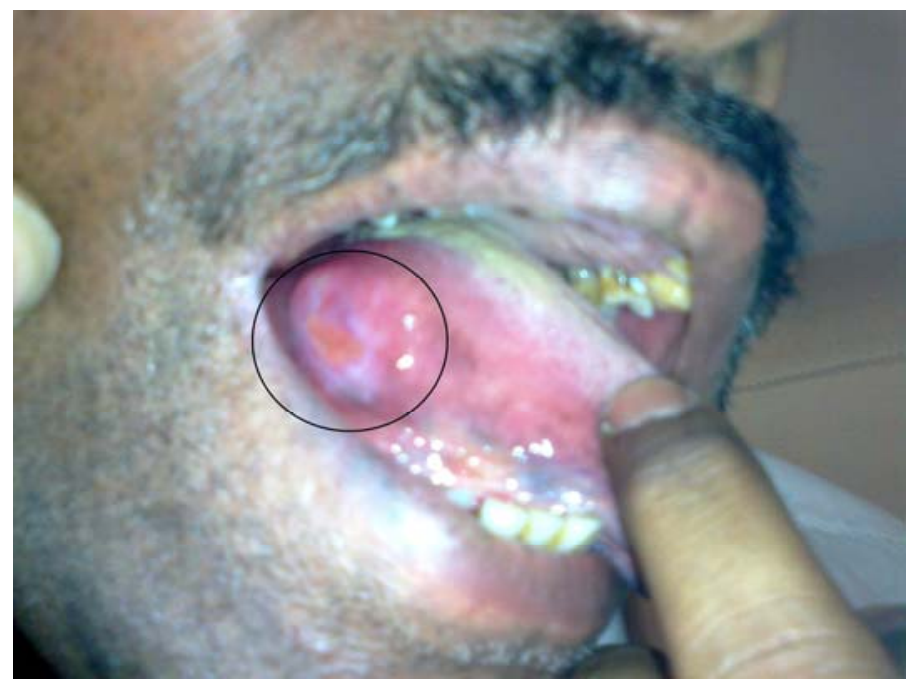

Figure 2. (a) Immunohistochemistry of tongue lesion showing vimentin positivity, (b) Pan-CK positivity, (c) H\& E of tongue lesion showing infiltrative nests of clear cells and (d) neoplastic clear cells from nephrectomy specimen.

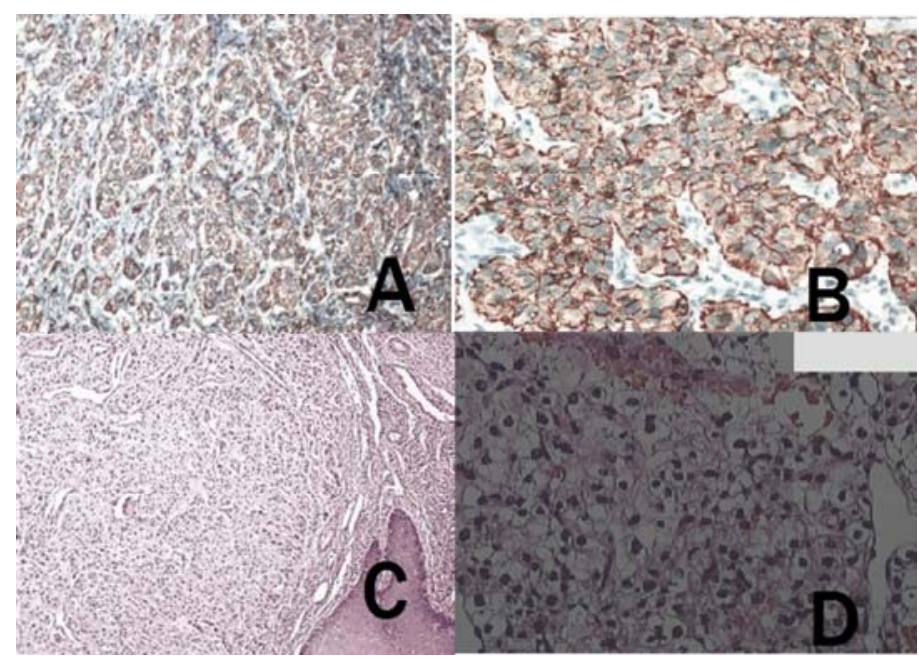


Figure 3. Palliative radiotherapy to gross tumor volume was given with intra-oral electron therapy using $5 \mathrm{~cm}$ acrylic applicator

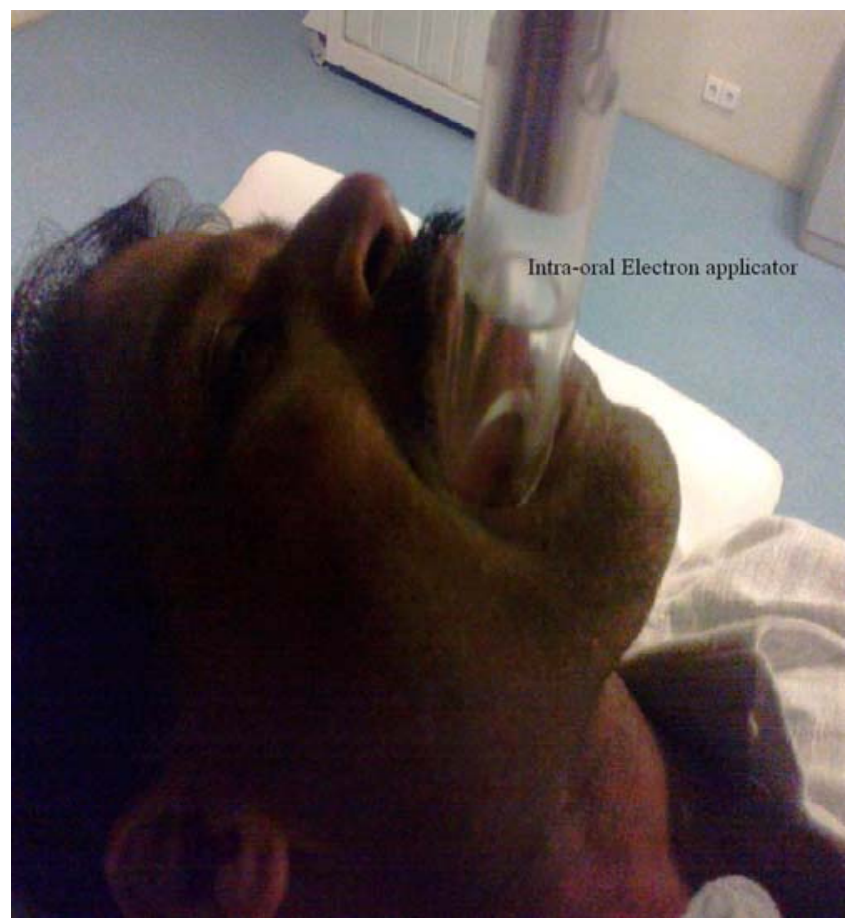

\section{Discussion}

RCC may remain clinically occult for most of its course and the tumor in the kidney can progress unnoticed to a large mass until metastatic disease appear. About 75\% of patients with metastatic RCC metastasize to lungs, liver and bones. Only $15 \%$ of RCC metastasize to the head and neck region especially into the paranasal sinuses, larynx, mandibles, thyroid and parotid glands ${ }^{[2,3]}$. Tongue metastasis as an initial manifestation of RCC is extremely rare with only 30 case reports have been reported since $1911^{[4]}$.

The possible routes for tongue metastasis suggested are the hematogenous and lymphatic circulation. The presences of valve less interconnecting vertebral veins allow intra-abdominal metastases to bypass the heart and lungs and communicate directly with the veins of the head and neck region. The vertebral veins in turn communicate superiorly with the pterygoid plexus, cavernous sinus and superior portion of the pharyngeal plexus, hence providing a pathway for metastasis to the tongue ${ }^{[6]}$. Involvement of base of tongue in our patient could be due to because of its rich vascularity and immobility as compared to the oral tongue. Head and neck metastasis is commonly associated with pulmonary metastasis as in our patient.

The treatment of tongue metastasis is the surgical excision, radiation therapy and novel agents such as sorafenib, sunitinib, temsirolimus ${ }^{[7]}$. We achieved complete regression of metastatic tongue disease with palliative radiation therapy with electrons in our patient.

The head and neck metastasis of RCC has poor prognosis and expected 5 year survival is less than $10 \%$, therefore all treatment options for head and neck metastasis are with palliative intent ${ }^{[8]}$. 
In conclusion, tongue metastases are rare manifestations and carry poor prognosis because most of these patients have widespread underlying metastatic disease. Clinical and histologic differentiation between metastatic and primary tongue carcinomas is very important as both have different treatment options.

\section{Conflict of interest}

Authors declare that there is no conflict of interest statement.

\section{References}

[1] Tunio MA, Hashmi A, Rafi M. Need for a new trial to evaluate postoperative radiotherapy in renal cell carcinoma: A meta-analysis of randomized controlled trials.

[2] Tunio MA, Hashmi A, Rafi M. Epistaxis and proptosis - Unusual primary manifestations of metastatic renal cell carcinoma. Pak J Med Sci 2009;25:1012-14

[3] Tunio MA, Hashmi A, Rafi M. Renal cell carcinoma presenting as skin and ipsilateral testicular metastasis. Isra Medical Journal 2009;1:79-81

[4] Azam F, Abubakerr M, Gollins S. Tongue metastasis as an initial presentation of renal cell carcinoma: A case report and literature review. J Med Case Reports 2008;2:249. PMid:18657269 http://dx.doi.org/10.1186/1752-1947-2-249

[5] Will TA, Agarwal N, Petruzzelli GJ. Oral cavity metastasis of renal cell carcinoma: A case report. J Med Case Reports 2008;2:313. PMid:18823541 http://dx.doi.org/10.1186/1752-1947-2-313

[6] Kaminski B, Kobiorska-Nowak J, Bien S. Distant metastases to nasal cavities and paranasal sinuses, from the organs outside the head and neck. Otolaryngology Pol 2008;62:422-25. PMid:18837216

[7] Rabinovitch RA, Zelefsky MJ, Gaynor JJ, Fuks Z. Patterns of failure following surgical resection of renal cell carcinoma: Implication for adjuvant local and systemic therapy. J Clin Oncol 1994;12:206-12 PMid:8270978

[8] Aguirre A, Rinaggio J. Lingual metastasis of renal cell carcinoma. J Oral Maxillofac Surg 1996;4:344-46.

http://dx.doi.org/10.1016/S0278-2391(96)90757-0 